\title{
FOUR YEARS OF SURVEILLANCE OF RECENT HIV INFECTIONS AT COUNTRY LEVEL, FRANCE, MID 2003 - 2006 : EXPERIENCE AND PERSPECTIVES
}

\author{
Caroline Semaille (c.semaille@invs.sante.fr) ${ }^{1}$, F Cazein ${ }^{1}$, J Pillonel ${ }^{1}$, F Lot ${ }^{1}$, S Le Vu ${ }^{1}$, R Pinget ${ }^{1}$, J C Desenclos ${ }^{1}$, F Barin ${ }^{2}$ \\ 1. Institut de veille sanitaire (French Institute for Public Health Surveillance), Saint-Maurice, France \\ 2. Université François-Rabelais, Inserm ERI 19, Centre National de Référence du VIH, CHU Bretonneau, Tours, France
}

\begin{abstract}
New systems of surveillance to better monitor the dynamics of HIV are needed. A national surveillance of new HIV diagnoses which included the collection of dried serum spots (DSS) to identify recent infections ( $<6$ months) using an EIA-RI assay was implemented in 2003 in France. The collection of DSS is based on the voluntary participation by both patients and microbiologists. Multivariate analysis was used to identify factors associated with recent infection (RI). Between July 2003 and December 2006, 14,155 cases newly diagnosed for HIV were reported. A minority of patients refused the collection of DSS (3.3\%) and the rate of participation of laboratories was $80 \%$. The test was performed for 10,855 newly diagnosed HIV cases, the overall proportion of $\mathrm{RI}$ was $23.1 \%(95 \% \mathrm{Cl}, 22.3 \%-23.9 \%)$. The proportion of $\mathrm{RI}$ was higher among men who have sex with men (MSM) $(42.8 \%)$ than among heterosexuals (16.3\%). Among heterosexuals, it varied by current nationality: $27 \%$ among French versus $8.4 \%$ among Africans. The risk of $\mathrm{RI}$ was greater for MSM ( $\mathrm{aOR}=1.8)$, those of French nationality $(\mathrm{aOR}=3.9)$, those with high-economic status $(\mathrm{aOR}=1.2)$, those tested after a risk exposure $(\mathrm{aOR}=1.4)$, those tested for HIV three or more times during their lifetime $(\mathrm{aOR}=2.5)$. The risk of $\mathrm{RI}$ decreased with age. A nation-wide implementation of RI monitoring is feasible. The information on RI is very useful for renewing prevention messages, particularly among population in which HIV transmission is on going, such as MSM.
\end{abstract}

\section{Background}

In most industrialized countries, HIV/AIDS routine surveillance is based on case reporting to monitor new diagnoses. Having the characteristics and trends of newly diagnosed HIV or AIDS cases is essential but not sufficient to monitor the dynamic of HIV transmission. Therefore, several countries implemented the surveillance of recent HIV infections at either regional or national level for a given period (e.g. Australia, Austria) or have started this monitoring recently (USA, Germany) $[1,2]$. To our knowledge, France is the only country where recent infection (i.e. infection acquired in the last six months) has been routinely monitored at the national level since 2003 among patients newly diagnosed with HIV [3].

This monitoring, defined as "virological surveillance" (VS), uses dried serum spots (DSS) taken at the same time as HIV diagnosis and notification. Here, we report the results of the first four years of this virological surveillance from July 2003 to December 2006.
We also discuss the challenges in implementing such surveillance, the possibilities to introduce it in other countries, and the ways to use its results for public health action.

\section{Methods}

\section{Case reporting of HIV}

Mandatory anonymous HIV case reporting was implemented in France in 2003, and the procedures have been described previously [4]. The following patient characteristics are collected and entered into the national database: sex, age, country of birth, current nationality, region of residency, mode of transmission, socioprofessional category, clinical stage at the time of HIV diagnosis (primary infection, asymptomatic stage, symptomatic not AIDS stage, AIDS stage), number of previous HIV tests and reasons for HIV screening. In this article, we analyze new HIV diagnoses dated from 1 July 2003 to 31 December 2006 which were reported to the Institut de Veille Sanitaire (InVS), the French Institute for Public Health Surveillance, up to March 2007.

The estimated proportion of under-reporting of new HIV diagnoses in France varies from 34 to $40 \%$, depending on the year of diagnosis $(40 \%, 37 \%, 34 \%, 36 \%$ in 2003, 2004, 2005, 2006 respectively). Every year, the estimated proportion of underreporting and the reporting delay are based on the comparison between the number of HIV notifications and the number of positive serology results reported by all laboratories in France [5]. The case definition of new HIV diagnosis used in both systems is similar.

In this article the proportion of under-reporting and the reporting delay are taken into account when presenting the absolute numbers of recent infections in the results part. These absolute numbers were calculated separately for each year in order to take into account the different proportions of under-reporting which varied each year.

\section{Virological surveillance}

DSS was used to determine for each new HIV diagnosis whether or not the HIV infection was recent, i.e. occurred less than six months before diagnosis. For each case, the laboratory that made the original diagnosis was asked to take DSS from the stored serum sample and send it under the patient's anonymous code to the National Reference Center (NRC) by postal mail. Results from the NRC were then sent to InVS and linked to the epidemiological data 
in the HIV national database using the patient's anonymous code. Although HIV notification is mandatory, VS is based on the voluntary participation by both microbiologists and patients. The patient's consent for VS is obtained by the reporting clinician through the HIV notification form.

\section{Immunoassay to identify recent infections (EIA-RI)}

The characteristics and properties of this assay have been described previously, and are also discussed in the article from $J$ Parry et al. in this special issue of Eurosurveilllance [6]. Based on early evaluation of EIA-RI we estimated that this assay using DSS would be able to identify recent infections (RI) among all infected patients with HIV-1 (without AIDS) with a sensitivity of $87 \%$ and a specificity of $98 \%$. The EIA-RI may misclassify patients at the AIDS stage as recently infected, and therefore patients known to have AIDS (information collected from the HIV reporting form) were classified as established infection whatever the result of the EIA-RI.

\section{Statistical analysis}

The chi test for trend was used to analyze the trend overtime of the proportion of recent infections among newly diagnosed HIV cases. The proportions were compared using standard chisquare tests. Variables that were significantly associated with recent infection status in the univariate analysis were entered in a multiple logistic regression model to identify factors independently associated to recent infections (using a global test). The goodness of fit was assessed by the Hosmer-Lemeshow test. All analyses were conducted with SAS $®$ software version 08 , and statistical significance was considered for $p$ values $<0.05$

\section{Results}

\section{Description of new HIV-1 diagnoses}

Between July 2003 and December 2006, 14,155 newly diagnosed HIV cases were reported to the InVS. Males accounted for $61 \%$ of cases. More than half $(53 \%)$ of the newly diagnosed HIV infections were attributed to heterosexual contact, whereas men who have sex with men (MSM) accounted for $25 \%$ of the cases (Table 1). Those infected through drug use constituted a low percentage of all cases $(2 \%, n=306)$. Concerning the nationality of cases, one third $(31 \%, n=4,383)$ came from sub-Saharan countries, and were mainly infected by heterosexual contact. The reasons for screening and the clinical stage at the time of HIV diagnoses varied by transmission categories. The proportion of cases that have undergone voluntary screening after an exposure is

T A B L E

Newly diagnosed HIV cases by sex and transmission category, France, July 2003 - December $2006(n=14,155)$

\begin{tabular}{|c|c|c|c|}
\hline Transmission category & $\begin{array}{l}\text { Women } \\
\mathrm{N}(\%)\end{array}$ & $\begin{array}{l}\text { Men } \\
\text { N (\%) }\end{array}$ & $\begin{array}{l}\text { Total } \\
\text { N (\%) }\end{array}$ \\
\hline MSM & & $3,579(41.6)$ & $3,579(25.3)$ \\
\hline $\begin{array}{l}\text { Heterosexuals } \\
\text { Sub-Saharian Africa } \\
\text { France } \\
\text { Other/unknow }\end{array}$ & $\begin{array}{l}4,384(79.1) \\
-2,359 \\
-1,150 \\
-875\end{array}$ & $\begin{array}{l}3,168(36.8) \\
-1,281 \\
-1,234 \\
-653\end{array}$ & $\begin{array}{l}7,552(53.4) \\
-3,640 \\
-2,384 \\
-1,528\end{array}$ \\
\hline Drug users & $64(1.2)$ & $242(2.8)$ & $306(2.2)$ \\
\hline Other * & $9(0.1)$ & $9(0.1)$ & $18(0.1)$ \\
\hline Unknown & $1,084(19.6)$ & $1,616(18.7)$ & $2,700(19.0)$ \\
\hline
\end{tabular}

MSM = men who have sex with men

*Hemophilia or transfusion recipient greater among MSM than among heterosexuals (33\% vs 19\%), and it is higher among French heterosexuals than African heterosexuals ( $22 \%$ vs $18 \%$ ). The proportion of cases newly diagnosed at the time of primary infection ('primary infection' as filled in by clinicians whatever the results of the test of recent infection) was greater among MSM than among heterosexuals (19 vs $5 \%$ ).

\section{Recent infections among new HIV-1 diagnoses}

From July 2003 to December 2006, the test for RI was performed for 10,855 new HIV diagnoses. Results were not obtained for 3,300 patients either because the laboratory did not submit DSS to the NRC (2,834 cases representing $20 \%$ of all new HIV diagnoses) or the patient did not consent to participation (466 cases, 3.3\%). These cases were excluded from further analysis. Among the excluded cases, the proportion of MSM and of French nationals was lower than among the cases included in the investigation (19\% vs $27 \%$ and $39 \%$ vs $46 \%$, respectively), whereas the proportion of cases with unknown mode of transmission and unknown nationality was higher than among the included cases (24\% vs $18 \%$ and $16 \%$ vs $13 \%$, respectively).

The proportions of patients who refused to participate and of laboratories that did not send DSS for analysis were stable over time.

Among the newly diagnosed HIV-1 cases that were included in the analysis, 2,511 were identified as recent with the EIA-RI test $(23.1 \%, 95 \% \mathrm{Cl}=22.3-23.9)$. After adjustment for under-

T A B L E 2

Proportion of recent infections among new HIV-1 diagnoses, France, July 2003 - December 2006 ( $n=10,855$ newly diagnosed HIV-1 cases, of whom 2,511 were identified as recent)

\begin{tabular}{|c|c|c|c|c|}
\hline & $\begin{array}{l}\text { Number } \\
\text { of recent } \\
\text { infections }\end{array}$ & $\begin{array}{l}\text { Proportion } \\
\text { of recent } \\
\text { infections }\end{array}$ & [IC $95 \%$ ] & $p^{*}$ \\
\hline Sex & & & & $p<10^{-4}$ \\
\hline Male & 1863 & 27.8 & {$[26,8-28,9]$} & \\
\hline Female & 648 & 15.6 & {$[14,5-16,7]$} & \\
\hline Age group (years) & & & & $p<10^{-4}$ \\
\hline $15-29$ & 756 & 26.0 & {$[24,4-27,6]$} & \\
\hline $30-39$ & 969 & 24.3 & {$[22,9-25,6]$} & \\
\hline $40-49$ & 499 & 21.0 & {$[19,4-22,7]$} & \\
\hline$>=50$ & 287 & 18.1 & {$[16,2-20,0]$} & \\
\hline Transmission category* & & & & $p<10^{-4}$ \\
\hline Homosexual & 1263 & 42.8 & {$[41,0-44,6]$} & \\
\hline Heterosexual & 939 & 16.3 & {$[15,4-17,3]$} & \\
\hline Drug users & 33 & 14.6 & {$[10,0-19,2]$} & \\
\hline Other/Unknown & 276 & 14.3 & {$[12,8-15,9]$} & \\
\hline Current Nationality & & & & $p<10^{-4}$ \\
\hline France & 1707 & 34.4 & {$[33,1-35,7]$} & \\
\hline Europe (outsideFrance) & 59 & 24.1 & {$[18,7-29,4]$} & \\
\hline Sub-Saharian Africa & 285 & 8.4 & {$[7,4-9,3]$} & \\
\hline North Africa & 40 & 18.6 & {$[13,4-23,8]$} & \\
\hline Other/Unknown & 420 & 20.7 & {$[18,9-22,5]$} & \\
\hline
\end{tabular}

${ }^{*}$ chi ${ }^{2}$ test 
TA B L E 3

Factors independently associated with recent infections among new HIV-1 diagnoses. Results from the multivariate analysis

France, July 2003 - December 2006 ( $n=10,855$ newly diagnosed HIV-1 cases, of whom 2,511 were identified as recent)

\begin{tabular}{|c|c|c|c|c|c|c|c|c|c|}
\hline & \multirow[b]{2}{*}{$\begin{array}{l}\text { Number of } \\
\text { subjects }\end{array}$} & \multicolumn{4}{|c|}{ Univariate analysis } & \multicolumn{4}{|c|}{ Multivariate analysis } \\
\hline & & OR & $95 \%$ & CI & p value ${ }^{a}$ & $\mathrm{aOR}$ & $95 \%$ & CI & p value ${ }^{a}$ \\
\hline \multicolumn{10}{|l|}{ Sex and transmission category } \\
\hline Male heterosexual & 2,414 & 1 & & & $<0.0001$ & 1 & & & $<0.001$ \\
\hline Male homosexual & 2,949 & 4.07 & 3.57 & 4.65 & & 1.85 & 1.59 & 2.15 & \\
\hline Other/unknown male & 1,332 & 1.10 & 0.92 & 1.32 & & 0.85 & 0.71 & 1.04 & \\
\hline Female heterosexual & 3,340 & 1.10 & 0.96 & 1.27 & & 1.12 & 0.96 & 1.32 & \\
\hline Other/unknown female & 820 & 0.62 & 0.48 & 0.80 & & 0.50 & 0.38 & 0.66 & \\
\hline \multicolumn{10}{|l|}{ Age group (years) } \\
\hline$\geq 50$ & 1,587 & 1 & & & $<0.001$ & 1 & & & $<0.0001$ \\
\hline $15-29$ & 2,905 & 1.59 & 1.37 & 1.85 & & 1.92 & 1.62 & 2.28 & \\
\hline $30-39$ & 3,991 & 1.45 & 1.25 & 1.68 & & 1.43 & 1.22 & 1.67 & \\
\hline $40-49$ & 2,372 & 1.21 & 1.03 & 1.42 & & 1.12 & 0.94 & 1.33 & \\
\hline \multicolumn{10}{|l|}{ Current nationality } \\
\hline Sub-Saharan Africa & 3,405 & & & & $<0.0001$ & 1 & & & $<0.001$ \\
\hline France & 4,962 & 5.74 & 5.02 & 6.57 & & 3.95 & 3.36 & 4.64 & \\
\hline Other/unknown foreign country & 2,488 & 2.89 & 2.47 & 3.37 & & 2.59 & 2.18 & 3.08 & \\
\hline \multicolumn{10}{|l|}{ Reasons for HIV testing } \\
\hline Pregnancy \& systematic screening & 1,934 & 1 & & & $<0.001$ & 1 & & & $<0.001$ \\
\hline Clinical symptoms or biological data & 3,677 & 1.51 & 1.31 & 1.74 & & 1.20 & 1.02 & 1.40 & \\
\hline Exposure & 2,382 & 2.39 & 2.06 & 2.78 & & 1.38 & 1.17 & 1.63 & \\
\hline Others & 1,768 & 1.37 & 1.16 & 1.62 & & 0.86 & 0.72 & 1.04 & \\
\hline Unknown & 1,094 & 1.49 & 1.24 & 1.80 & & 1.16 & 0.93 & 1.43 & \\
\hline \multicolumn{10}{|l|}{ Professional category } \\
\hline Unknown and non-professional activity & 4,816 & 1 & & & $<0.001$ & 1 & & & 0.014 \\
\hline Employee & 2,079 & 1.70 & 1.51 & 1.92 & & 1.10 & 0.95 & 1.26 & \\
\hline Blue collar & 1,454 & 1.03 & 0.89 & 1.20 & & 0.91 & 0.77 & 1.09 & \\
\hline High level staff & 2,506 & 2.16 & 1.94 & 2.42 & & 1.17 & 1.02 & 1.35 & \\
\hline \multicolumn{10}{|l|}{ Testing frequency (during the whole life) } \\
\hline One HIV test & 3,804 & 1 & & & $<0.001$ & 1 & & & $<0.001$ \\
\hline Two HIV tests & 2,731 & 1.65 & 1.45 & 1.87 & & 1.47 & 1.28 & 1.68 & \\
\hline Three or more HIV tests & 1,474 & 4.42 & 3.85 & 5.08 & & 2.51 & 2.16 & 2.93 & \\
\hline Unknown & 2,846 & 2.15 & 1.90 & 2.43 & & 1.91 & 1.66 & 2.20 & \\
\hline \multicolumn{10}{|l|}{ Year of diagnosis } \\
\hline Second semester 2003 & 1,628 & 1 & & & 0.65 & & & & \\
\hline 2004 & 3,160 & 0.97 & 0.84 & 1.11 & & & & & \\
\hline 2005 & 3,397 & 1.04 & 0.90 & 1.19 & & & & & \\
\hline 2006 & 2,670 & 0.98 & 0.85 & 1.14 & & & & & \\
\hline \multicolumn{10}{|l|}{ Region of residency } \\
\hline Outside Paris area & 5,661 & 1 & & & 0.0007 & 1 & & & 0.14 \\
\hline Paris area & 5,194 & 1.17 & 1.07 & 1.28 & & 0.93 & 0.84 & 1.03 & \\
\hline
\end{tabular}

a global test, CI confidence interval

Note : Hosmer- Lemeshow statistic: $\mathrm{chi}^{2}=10,53 ;$ d.f. $=8 ; p=0.23$ 
reporting and reporting delays, the number of recent infections that occurred from mid 2003 to 2006 was estimated at around 4,000 . Half of these cases (estimated at 2,010) were among men who have sex with men (MSM): representing 550 to 600 MSM per year. The number of drug users recently infected was very low (52 cases over the whole period). From 2003 to 2006, the adjusted number of cases newly diagnosed and identified as recent was greater among French heterosexually infected persons (805) than among sub-Saharan Africans living in France (454 cases).

The proportion of $\mathrm{RI}$ was higher in MSM (42.8\%) than in heterosexuals (16.3\%) (Table 2 ). Among heterosexuals, it varied by current nationality: $27.0 \%$ among French versus $8.4 \%$ among Africans $(p<0.001)$. The year of diagnosis was not associated with recent infection in the univariate analysis. In the multivariate analysis the risk of recent infection was greater for MSM ( $a O R=1.8)$, those of French nationality $(\mathrm{aOR}=3.9)$, those of a high socioeconomic status $(\mathrm{aOR}=1.2)$, those tested for HIV after a risk exposure $(\mathrm{aOR}=1.4)$ and those who had undergone three or more tests during their lifetime $(\mathrm{aOR}=2.5)$ (Table 3$)$. However, the risk of $\mathrm{RI}$ decreased with age. Although the region of residency was not independently associated with recent infection $(p=0.14)$, this variable was maintained in the model because it improved the goodness of fit $(p=0.23)$.

\section{Discussion}

We found that a little less than one quarter of the newly diagnosed patients included in the study had been infected with HIV within the last six months. Among the newly diagnosed MSM, half had been infected recently This is consistent with results reported in several more restricted studies: the proportion of recent infections among new HIV diagnoses was 27\% in Austria in 2002-2003, $26 \%$ in Switzerland in 2005-2006, 20\% in ten cities in the United States in 1997-2001, and 45\% among MSM in United Kingdom in 2005 , and $36 \%$ in a study which mainly involved MSM in the Victoria region of Australia in 1999-2000 [1,2,7-9].

The proportion of recent infections should be interpreted with some caution because it depends on both testing patterns and HIV incidence. This is consistent with our analysis which found that the number of lifetime HIV tests performed is strongly associated with $\mathrm{RI}$, and that the chance of detecting recent infections increased with the number of tests. Similarly, people screened for HIV after a risk-exposure are more likely to be diagnosed as a recent infection $(\mathrm{aOR}=1.4)$ than those screened for pregnancy.

Our results indicate that the largest population diagnosed as recently infected in France is the MSM population. This may result from both a relatively high HIV incidence and a more frequent testing among MSM. These findings are supported by other sources of epidemiological data which indicate that MSM have been engaging in high-risk sexual behaviors in recent years in France: (i) increase in the proportion of unprotected anal intercourse from 19\% in 1997 to 33\% in 2004 (Enquête Presse Gay 1997 and 2004) (ii) outbreak of syphilis ongoing since 2000, and (iii) emergence of rectal lymphogranuloma venereum in 2004 [10-12]. Behavioral surveys have also shown that MSM are more frequently tested for HIV: half of MSM were tested during the last 12 months before the study, whereas in the general population only $11 \%$ underwent testing during the last year $[10,13,14]$. However, the multivariate analysis, taking into account the variable "testing frequency" has identified MSMs as the subgroup with the highest risk of being recently infected.
Current nationality was also found to be strongly associated with RI. Persons of African origin were less likely to be diagnosed as a recent infection than French and other foreign nationalities. This may reflect the fact that HIV-positive Africans living in France are mostly immigrants who could have been infected with HIV many years before in their country of origin where HIV prevalence is high, and diagnosed only recently in France. A survey conducted in 2005 among the African community living in the Paris area showed that the testing frequency in this group was higher than expected: $65 \%$ of African respondents had been screened for HIV at least once in their life, compared to $51 \%$ in the general population (in 2004) $[14,15]$. However, the proportion of recent infections among newly diagnosed Africans living in France which we estimated to be $8 \%$ indicates that HIV transmission also occurred in this community while living in France.

The proportion of recent infections among drug users was found to be very low, and while surveys have shown that most drug users are aware of their HIV serostatus, these results reflect the positive impact of the harm-reduction strategy implemented in France since the beginning of the 1990s [16].

Socio-professional categories associated with high economic status were also independently related to the fact of being diagnosed as recent. This may reflect both a better access to HIV screening and a better assessment of the risk of HIV infection in this welleducated population with ongoing risk behaviors.

The proportion of cases with recent infection at the time of HIV diagnosis was also found to be higher among younger age groups, which can be explained by the fact that the probability of having a recent infection at the time of diagnosis increases with shorter exposure to the risk. Also, we need to take into account that in France young people are more frequently tested for HIV than older people (17\% among $18-24$ years old vs $4 \%$ among $45-54$ years old) [14]

Our results have shown that the proportion of $\mathrm{RI}$ was stable between 2003 and 2006, and in the univariate analysis the year of diagnosis was not associated with the recent infection diagnosis. In parallel, HIV screening policies did not change during this period in France, and the rate of HIV screening per 100,000 population did not vary considerably (range from 79 to 81 per 100,000 depending on years) [17].

\section{How feasible is the implementation of monitoring of recent} infections among new diagnoses in other developed countries?

Our report summarizes the results of four years of long-term national monitoring of HIV infection by combining the surveillance of recent HIV infection with HIV case reporting. To our knowledge, France is the first country to have implemented such an integrated system at a national level. This was made feasible by using an assay which could be performed on samples collected on filter paper thus making the management and the cost of recent infections monitoring reasonable. The costs were estimated at around three euros per case (including filter paper, a hermetically sealable plastic bag for transportation, reagents, and the time spent by a technician to perform the test). This amount did not include the cost of validation and data entry performed at InVS. Furthermore, a DSS can also be used to determine the group, type and subtype of the virus by a serotyping method, and to genotype the virus in order to monitor the diversity of circulating viruses more closely 
$[3,18,19]$. The EIA-RI assay used in France can also be used in other countries. Although the technique is transferable, other assays could also be chosen (see the article of J Parry et al.).

The nation-wide implementation of recent infections monitoring seems feasible in other countries. It has been possible in France with the collaboration of a very high number of laboratories (around 4,300 ) that perform HIV diagnosis and send the DSS to the NRC. However, the project requires a lot of continuous effort to inform and encourage thousands of laboratories to participate and sustain their collaboration overtime. The participation of laboratories in the voluntary virological surveillance is good (around 80\%) and it is also well accepted by the patients (only 3\% do not consent to participate). Knowing that other European countries do not have so many laboratories that perform HIV testing (their numbers range from a few dozens to a few hundreds), the implementation of a similar surveillance should, therefore, be more feasible than in France.

When starting the project we also had to resolve the ethical issue of informing or not the patients and their physicians about the patient's RI status. Considering that: a) the test for RI was designed for public health purposes and not for establishing an individual diagnosis as the positive predictive values are not high enough for diagnostic purposes; b) the information flow within the HIV notification channel is anonymous by law whereas giving back the results would mean maintaining correspondence between the anonymous code and the name of the patient; c) it is not clear whether the result (recent infection or not) would have an impact on the individual health since there is non consensus yet on the long term benefit of HAART during the early months of infection and contact tracing is not done in France; it was decided, after a collective discussion with patient associations and clinicians, not to inform either patients or physicians. Although this question was still being discussed at the time of implementation of the system, it ceased to be controversial when the first results of virological surveillance were reviewed with clinicians and patient associations and published in December 2003.

What is the impact of these results in terms of public health?

Nearly half of MSM newly diagnosed with HIV (43\%) were shown to have been recently infected. Subsequently, these findings were actively communicated to the gay communities in France and had a major impact. The feedback of this group to associations for the fight against AIDS is critical. Moreover, the findings were used in several prevention campaigns and prompted the Ministry of Health to renew the prevention messages. Nevertheless, the extent of HIV transmission in MSM remains alarming, illustrating the difficulty to target and sustain prevention in this usually well-educated population. However, the high proportion of RI also indicates that screening strategies have been effectively adopted by the gay community: MSM more often than other groups undergo testing for HIV soon after a risk exposure. The data on reasons for screening show that the proportion of those who undergo voluntary testing after an exposure is higher among MSM than among heterosexual individuals (33\% vs 19\%). Therefore, the proportion of RI among MSM could also be an indicator for screening patterns among this population that would be interesting to monitor.

Although we showed that the proportion of recent infections among the newly diagnosed HIV cases of African origin is much lower than among the general population, our results indicate that
HIV transmission in this group also occurs after arrival in France. In addition, we found out that one out of five newly diagnosed HIV cases of African origin were infected by subtype B, although this subtype is not common in Africa (data not shown in this article) $[3,17]$. The combination of these two results (proportions of RI and subtype B) has induced the Ministry of Health to adapt its policy regarding the African community living in France and encourage HIV screening and prevention within this population.

While the incidence of HIV infection has been previously estimated in defined risk groups such as prostitutes, IDUs, MSM attending STI clinics, this has not been done at the country level $[9,20,21]$. We are currently working on assessing the HIV incidence at the country level by combining, through mathematical modeling, the results of the test for recent infection with other factors such as screening patterns (see the article by S Le Vu et al. in this special issue of Eurosurveillance).

\section{Conclusion}

The information on recent infections is very useful for renewing prevention messages, particularly among populations in which HIV transmission is still ongoing, such as the gay community in France, and for promoting HIV testing among populations in which few recent infections have been identified. An overview of new testing strategies is ongoing in France in order to better define the use of the rapid HIV test on whole blood or serum samples, notably in a community context.

\section{Acknowledgements:}

We thank all participants in the national surveillance program, particularly microbiologists, physicians, and public health doctors. We thank Farida Mihoud for reviewing the manuscript in English. We thank Danielle David, Marlene Leclerc, Sophie Couturier, Betty Basselier, Sylvie Brunet, and Damien Thierry for their technical support to the HIV monitoring.

\section{References}

1. Guy RJ, Breschkin AM, Keenan CM, Catton MG, Enriquez AM, Hellard ME. Improving HIV surveillance in Victoria: the role of the "detuned" enzyme immunoassay. J Acquir Immune Defic Syndr 2005;38(4):495-9.

2. Puchhammer-Stockl E, Schmied B, Rieger A, Sarcletti M, Geit M, Zangerle R, et al. Low proportion of recent human immunodeficiency virus (HIV) infections among newly diagnosed cases of HIV infection as shown by the presence of HIV-specific antibodies of low avidity. J Clin Microbiol 2005;43(1):497-8.

3. Semaille C, Barin F, Cazein F, Pillonel J, Lot F, Brand D, et al. Monitoring the dynamics of the HIV epidemic using assays for recent infection and serotyping among new HIV diagnoses: experience after 2 years in France. J Infect Dis 2007;196(3):377-83.

4. Lot F, Semaille C, Cazein F, Barin F, Pinget R, Pillonel J, et al. Preliminary results from the new HIV surveillance system in France. Euro Surveill. 2004;9(10):pii=481. Available from: http://www.eurosurveillance.org/ ViewArticle.aspx?ArticleId $=481$

5. Cazein F, Pinget R. Surveillance du VIH : notification obligatoire et surveillance virologique. Lutte contre le VIH/sida et les infections sexuellement transmissibles en France - 10 ans de surveillance, 1996-2005. Saint Maurice: Institut de Veille Sanitaire; 2007. p. 14-24.

6 . Barin F, Meyer L, Lancar R, Deveau C, Gharib M, Laporte A, et al. Development and validation of an immunoassay for identification of recent human immunodeficiency virus type 1 infections and its use on dried serum spots. J Clin Microbiol 2005;43(9):4441-7.

7. Schupbach J, Gebhardt MD, Tomasik Z, Niederhauser C, Yerly S, Burgisser P, et al. Assessment of recent HIV-1 infection by a line immunoassay for HIV-1/2 confirmation. PLoS Med 2007;4(12):e343. 
8. Schwarcz S, Weinstock H, Louie B, Kellogg T, Douglas J, Lalota M, et al. Characteristics of persons with recently acquired HIV infection: application of the serologic testing algorithm for recent HIV seroconversion in 10 US cities. J Acquir Immune Defic Syndr 2007;44(1):112-5.

9. Fisher M, Pao D, Murphy G, Dean G, McElborough D, Homer G, et al. Serological testing algorithm shows rising HIV incidence in a UK cohort of men who have sex with men: 10 years application. AIDS 2007;21(17):2309-14.

10. Velter A. Comportements sexuels à risque vis-àvis du VIH et des IST et stratégies de réduction des risques sexuels. Rapport Enquête Presse Gay. Saint Maurice: Institut de veille Sanitaire; 2007. p. 15-32.

11. Bouyssou-Michel A, Gallay A, Janier M, Dupin N, Halioua B, Alcaraz I, et al. Surveillance de la syphilis en France, 2000-2006 : recrudescence des diagnostics en 2006. Bilans réguliers de surveillance - Infections sexuellement transmissibles. Bull Epidemiol Hebd 2008;(5-6):39-42.

12. Herida M, de Barbeyrac B, Sednaoui P, Scieux C, Lemarchand N, Kreplak G, et al. Rectal lymphogranuloma venereum surveillance in France 2004-2005. Euro Surveill. 2006;11(9):pii=647. Available from: http://www.eurosurveillance.org/ ViewArticle.aspx?ArticleId $=647$

13. Velter A, Michel A, Pillonel J, Jacquier G, Semaille C. Baromètre gay 2005 enquête auprès des hommes fréquentant les lieux de rencontre gay franciliens. Bull Epidemio Hebd 2006;(25):178-80.

14. Beltzer N, Lagarde M, Wu-Zhou X, Vongmany N, Grémy I. Les connaissances, attitudes, croyances et comportements face au VIH/Sida en France. Evolutions 1992 - 1994 - 1998 - 2001 - 2004. Paris: Observatoire régional de santé d’Ilede-France; 2005

15. Le Vu S. Connaissances et pratiques liées au dépistage du VIH. Les populations africaines d'Ile-de-France face au VIH/sida - Connaissances, attitudes, croyances et comportements.Saint-Denis: Institut national de prévention et d'éducation pour la santé; 2007. p. 129-43.

16. Jauffret-Roustide M, Couturier E, Le Strat Y, Barin F, Emmanuelli J, Semaille C, et al. Estimation de la séroprévalence du VIH et du VHC et profils des usagers de drogues en France, étude InVS-ANRS Coquelicot, 2004. Bull Epidemiol Hebd 2006;(33):244-7.

17. Institut de veille sanitaire, Centre National de Référence du VIH. Surveillance de l’infection à VIH/sida en France, 2006. Numéro thématique - L'infection à VIH/sida en France et en Europe. Bull Epidemiol Hebd 2007;(46-47):386-93.

18. Barin F, Plantier JC, Brand D, Brunet S, Moreau A, Liandier B, et al. Human immunodeficiency virus serotyping on dried serum spots as a screening tool for the surveillance of the AIDS epidemic. J Med Virol 2006;78 Suppl 1:S13-S18.

19. Barin F, Cazein F, Lot F, Pillonel J, Brunet S, Thierry D, et al. Prevalence of HIV-2 and HIV-1 group 0 infections among new HIV diagnoses in France: 2003-2006. AIDS 2007;21(17):2351-3.

20. Gupta SB, Murphy G, Koenig E, Adon C, Beyrer C, Celentano D, et al. Comparison of methods to detect recent HIV type 1 infection in cross-sectionally collected specimens from a cohort of female sex workers in the Dominican Republic. AIDS Res Hum Retroviruses 2007;23(12):1475-80.

21. Hu DJ, Vanichseni S, Mock PA, Young NL, Dobbs T, Byers RH Jr., et al. HIV type 1 incidence estimates by detection of recent infection from a cross-sectional sampling of injection drug users in Bangkok: use of the IgG capture BED enzyme immunoassay. AIDS Res Hum Retroviruses 2003;19(9):727-30.

This article was published on 4 September 2008.

Citation style for this article: Semaille C, Cazein F, Pillonel J, Lot F, Le Vu S, Pinget $R$, Desenclos JC, Barin F. Four years of surveillance of recent HIV infections at country level, France, mid 2003 - 2006: Experience and perspectives. Euro Surveill. 2008;13(36):pii=18968. Available online: http://www.eurosurveillance.org/ViewArticle. aspx?ArticleId $=18968$ 